\title{
Downregulated RRS1 inhibits invasion and metastasis of BT549 through RPL11-c-Myc-SNAIL axis
}

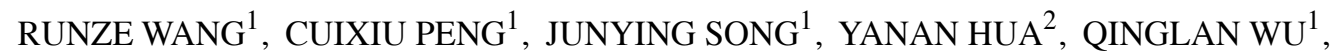

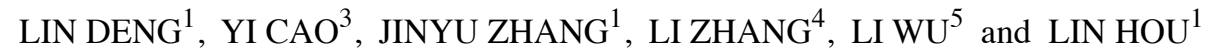 \\ Departments of ${ }^{1}$ Biochemistry and Molecular Biology and ${ }^{2}$ Neurobiology, Basic Medical College; \\ ${ }^{3}$ Department of Biochemistry, Medical College; ${ }^{4}$ Experimental Center for Undergraduates of Pharmacy, \\ School of Pharmacy; ${ }^{5}$ Department of Breast Center, The Affiliated Hospital of Qingdao University, \\ Qingdao University, Qingdao, Shandong 266000, P.R. China
}

Received November 4, 2021; Accepted February 4, 2022

DOI: $10.3892 /$ ijo.2022.5323

\begin{abstract}
Regulator of ribosome synthesis 1 (RRS1) is a key factor in ribosome biosynthesis and other cellular functions. High level of RRS1 in breast cancer cell lines is associated with increased cell proliferation, invasion and migration. RRS1 controls the assembly of the 60s subunit and maturation of $25 \mathrm{~S}$ rRNA during ribosome biosynthesis. In this study, lentiviral transfection of sh-RNA was used to knock down the level of RRS1, to detect the effect of RRS1 on cell function and to explore the specific mechanism of RRS1 affecting cell invasion and metastasis by COIP and dual-luciferase reporter gene assays. The present study found that RRS1 knockdown reduced the accumulation of ribosome protein L11 (RPL11) in the nucleolus, which then migrated to the nucleoplasm and bound to c-Myc. This inhibited trans-activation of SNAIL by c-Myc and eventually decreased the invasion and metastasis capacity of the human breast cancer cell line BT549. Taken together, RRS1 regulates invasion and metastasis of human breast cancer cells through the RPL11-c-Myc-SNAIL axis. The findings are of great significance for exploring the mechanism of breast cancer invasion and metastasis and the corresponding regulatory factors.
\end{abstract}

\section{Introduction}

Breast cancer is a highly prevalent malignancy among women and remains fatal in spite of the decrease in mortality rate in recent years (1). Clinically, three types of biomarkers are used to classify breast cancer: Estrogen receptor $\alpha$ (ER), progesterone receptor $(\mathrm{PR})$ and epidermal growth factor receptor 2

Correspondence to: Professor Lin Hou, Department of Biochemistry and Molecular Biology, Basic Medical College, Qingdao University, 308 Ningxia Road, Shinan, Qingdao, Shandong 266000, P.R. China E-mail: qingyi001@126.com

Key words: regulator of ribosome synthesis 1, ribosome protein L11, ribosome biosynthesis, breast cancer, invasion and metastasis
(HER-2) (2,3). Among them, Luminal A subtype highly expresses ER and PR, lacks HER-2 expression and has the characteristics of low proliferation rate and good prognosis (4). Luminal B subtype is similar to Luminal A subtype, but lacks PR expression. It demonstrates higher proliferation rate, worse prognostic effect and tolerance to hormone therapy (5). The HER-2 subtype is characterized by HER-2 overexpression, which can be further divided into HER-2 positive and HER-2 negative according to the expression of ER. It is more resistant to chemotherapeutics and the prognosis is worse than that of the Luminal subtypes. Triple negative breast cancer (TNBC) is characterized by absence of HER-2, PR and ER expression. It has strong chemotherapy resistance and metastasis. The prognosis of patients with triple-negative breast cancer is extremely poor and relapse common $(6,7)$. Distant organ metastasis, especially to the brain, bones, lungs and liver, is a characteristic feature of breast cancer $(8,9)$. Currently, metastatic breast cancer is treated by surgery, radiotherapy and adjuvant chemotherapy. Surgical resection has inherent disadvantages and is associated with high recurrence rates $(10,11)$, whereas radiotherapy and chemotherapy have a number of adverse effects, such as cardiac damage caused by combined chemoradiotherapy $(12,13)$. Therefore, it is critical to identify novel therapeutic targets for metastatic triple negative breast cancer (TNBC).

The ribosomal regulatory protein RRS1 was discovered in Saccharomyces cerevisiae by Tsuno et al in 1999 (14). The human RRS1 gene is located on chromosome 8q13.1 and contains only one exon (15). RRS1 regulates ribosome biosynthesis by recruiting $5 \mathrm{~S}$ ribonucleoprotein (RNP) to form the pre-60S ribosomal subunit with ribosomal production factor 2 (Rpf2) and promoting the maturation of 25S rRNA (16-18). RRS1 also mediates the export of pre-60S ribosomal subunit from the nucleolus to the cytoplasm. Thus, depletion of RRS1 results in the accumulation of the pre- 60 subunit in the nucleoplasm, eventually stalling ribosome biosynthesis (18). Studies show that RRS1 also regulates chromosome rearrangement during mitosis (19) and telomere aggregation (20) and serves an important role in delayed cell aging (21) and in the development of Huntington's disease (22). In addition, RRS1 is abnormally expressed in various cancers (23-30). 
Through binding of RPL11, which inhibits the interaction between RPL11 and murine doubleminute 2 (MDM2), it promotes the proliferation of breast cancer cells and reduces p53 levels (26). Knocking down RRS1 in breast cancer cells significantly reduced their proliferation rates by inducing cell cycle arrest (26).

RPL11 is a component of $5 \mathrm{~S}$ ribonucleoprotein particles (5S RNP) and is translocated to the nucleus along with RPL5 by the nuclear import protein Syo1, where they bind to $5 \mathrm{~S}$ rRNA (31). RPL11 regulates MDM2 (32), which prevents p53 accumulation during cellular stress by inducing protein ubiquitination and degradation (33-37). Furthermore, RPL11 suppresses c-Myc activity through a negative feedback pathway (38), which inhibits the transcription of downstream genes regulating cell growth, proliferation, metabolism, apoptosis, differentiation and ribosomal biosynthesis (39), whereas c-Myc can transcriptionally activate RPL11 (40). In addition, miR-150 and miR-383 suppresses 5S rRNA in esophageal squamous cell carcinoma cells, which strengthening RPL11-c-Myc interaction and reducing c-Myc-induced proliferation (41). C-myc regulates the epithelial mesenchymal transition (EMT) of various tumor cells (42-47), which allows the cells to detach from the primary tumors, extravasate and metastasize to distant organs (48).

The present study found that RRS1 regulated the invasion and metastasis of breast cancer cells through the RPL11-c-Myc-SNAIL axis. RRS1 knockdown disrupted ribosomal biosynthesis and prevented the export of RPL11 from the nucleus. The accumulation of RPL11 in the nucleoplasm inhibited c-Myc-dependent transcription of EMT-related genes. The findings revealed a new role of RRS1 in regulating breast cancer cell invasion and metastasis and demonstrate its potential as a therapeutic target.

\section{Materials and methods}

Cell line authentication. The breast cancer cell lines BT549, MDA-MB-231, MDA-MB-468, HMEC and MCF-7 was purchased from Procell Life Science \& Technology Co., Ltd. in March, 2021. The cell line was verified in March, 2021 and the follow-up experiments were performed in the same month. Briefly, DNA was extracted from $1 \times 10^{6}$ cells using Chelex 100 and 20 STR sites and sex loci were identified using the 21 CELL ID System (Procell Life Science \& Technology Co., Ltd.), including D19S433, D5S818, D21S11, D18S51, D6S1043, D3S1358, D13S317, D7S820, D16S539, CSF1PO, PentaD, vWA, D8S1179, TPOX, PentaE, TH01, D12S391, D2S1338, D1656 and Amelogenin1. The PCR products were analyzed with the ABI3130x1 genetic analyzer and Gene Mapper IDX software (Applied Biosystems; Thermo Fisher Scientific, Inc.) and compared with the ATCC, DSMZ, JCRB and Cellosaurus databases. BT549, MDA-MB-231, MDA-MB-468 are Triple negative breast cancer breast cancer. MCF-7 is Luminal A breast cancer. 293T cells were from the collection of our research group.

Cell culture and transfection. All the cell lines were cultured in Dulbecco's modified Eagle's medium (DMEM) supplemented with $10 \%$ FBS (Shanghai ExCell Biology, Inc.) and $1 \%$ penicillin and streptomycin solution at $37^{\circ} \mathrm{C}$. On reaching $20-30 \%$ confluency, the cells were transduced with the GV493-GFP lentivirus RNAi expression system (Shanghai GeneChem Co., Ltd.) expressing RPL11-shRNA or scrambled shRNA with Hitrans A\&P (Shanghai GeneChem Co., Ltd.). The multiplicity of infection (MOI) was 10 . The virus was transfected with serum-free medium for $10 \mathrm{~h}$ at $37^{\circ} \mathrm{C}$. The medium was changed and replaced with complete medium and subsequent experiments were carried out after culturing for $48 \mathrm{~h}$ at $37^{\circ} \mathrm{C}$. The siRNAs and scrambled sequence for siRNAs were synthesized by Sangon Biotech Co., Ltd. The target sequences for RPL11 were as follows: Forward 5'-GGUGCUGGAGUAUGA GUUATT-3' and reverse 5'-UAACUCAUACUCCCGCAC CTT-3'. The cell was transfected with siRNA using RNAFit (Hanbio Biotechnology Co., Ltd.) at $37^{\circ} \mathrm{C}$ according to the manufacturer's protocol.

Western blotting. Total protein was extracted from cells using RIPA buffer (Shandong Sparkjade Scientific Instruments Co., Ltd.) and quantified using a BCA kit (Beijing Solarbio Science \& Technology Co., Ltd.). Then $30 \mu \mathrm{g}$ of protein per sample was resolved by $10 \%$ SDS-PAGE and blotted onto PVDF membranes. After blocking with 5\% BSA (Beijing Solarbio Science \& Technology Co., Ltd., A8020) for $2 \mathrm{~h}$ at room temperature, the membranes were incubated overnight with primary antibodies against RRS1 (1:1,000; Abcam; cat. no. ab188161), c-Myc (1:1,000; Abcam; cat. no. ab32072), NPM1 (1:1,000; Proteintech; cat. no. 60096-1-Ig), Lamin B1 (1:1,000; Proteintech; cat. no. 12987-1-AP), N-cadherin (1:1,000; Proteintech; cat. no. 22018-1-AP), E-cadherin (1:1,000; Proteintech; cat. no. 20874-1-AP), c-Myc (1:1,000; Proteintech; cat. no. 67447-1-Ig), RPL11 (1:1,000; Proteintech; cat. no. 16277-1-AP), Vimentin (1:1,000; Proteintech; cat.no. 10366-1-AP), RPL23 (1:1,000; ABclona; cat. no. A4292) and Snail (1:1,000; ABclona; cat. no. A11794) at $4^{\circ} \mathrm{C}$, followed by the secondary antibodies at room temperature $(1: 3,000$, Bioss; cat. nos. bs-40296G-HRP and bs-40295G-HRP) for $1 \mathrm{~h}$. The positive bands were visualized using enhanced chemiluminescence (ECL) kit and the bands were measured using ImageJ (v1.53, National Institutes of Health).

Cell proliferation assay. BT549 cells were seeded into 96-well plates at the density of 2,000 cells/well. After 1,2,3,4, 5 days of incubation at $37^{\circ} \mathrm{C}, 10 \mu \mathrm{l}$ of CCK8 solution (Beijing Solarbio Science \& Technology Co., Ltd.) solution was added to each well and the cells were incubated for $2 \mathrm{~h}$ at $37^{\circ} \mathrm{C}$. The absorbance at $450 \mathrm{~nm}$ was measured using a microplate reader.

Reverse transcription-quantitative $(R T-q) P C R$ analysis. Total RNA was extracted by adding $1 \mathrm{ml}$ of TRIzol ${ }^{\circledR}$ Reagent (Thermo Fisher Scientific, Inc.) per $2 \times 10^{6}$ cells and using M-MLV Reverse Transcriptase (HiScript ${ }^{\circledR}$ III All-in-one RT SuperMix kit, Vazyme Biotech Co., Ltd.) reverse transcription $1 \mu \mathrm{g}$. qPCR was performed using the ChamQ Universal SYBR qPCR Master Mix (Vazyme Biotech Co., Ltd.) on ABI QuantStudio 3 (Applied Biosystems; Thermo Fisher Scientific, Inc.). The PCR amplification conditions were: Pre-denaturing at $95^{\circ} \mathrm{C}$ for $30 \mathrm{sec}$, followed by 45 cycles of denaturing at $95^{\circ} \mathrm{C}$ for $30 \mathrm{sec}$, annealing at $60^{\circ} \mathrm{C}$ for $30 \mathrm{sec}$ and the melting curve was the system default. The relative gene expression levels were normalized to GAPDH. The primer sequences were as 
follows: RRS1 Forward: 5'-CCCTACCGGACACCAGAG TAA-3', Reverse: 5'-CCGAAAAGGGGTTGAAACTTCC-3'; GAPDH Forward: 5'-AGAAGGCTGGGGCTCATTTG-3', Reverse: 5'-AGGGGCCATCCACAGTCTTC-3'. The above experiments followed the manufacturer's protocol. The relative expression levels were calculated using the $2^{-\Delta \Delta C a}$ method (49).

Transwell and invasion assay. Transwell units were used to measure the migration and invasion capacity of BT549 cells in vitro. BT549 cells were seeded into the upper compartment of Transwell inserts (Corning, Inc.) at the density of 10,000 cells/well in serum-free media. For the invasion assay, the inserts were coated with Matrigel ( $35 \mu \mathrm{l}$ per Transwell unit; diluted 1:8 with serum-free DMEM) at $4^{\circ} \mathrm{C}$ and incubated at $37^{\circ} \mathrm{C}$ for $2 \mathrm{~h}$ to gel the Matrigel. The lower compartments were filled with complete media. After $48 \mathrm{~h}$ of culture, the cells remaining on the upper surface of the membranes were removed with a cotton swab and those that migrated/invaded through the membranes were fixed with $4 \%$ paraformaldehyde for $10 \mathrm{~min}$ at room temperature and then stained with $0.1 \%$ hexamethylpararosaniline for $10 \mathrm{~min}$ at room temperature. Then three fields of view were randomly selected under an inverted microscope, images captured at x100 and x200 magnification, with counting and data analyzed from the $\mathrm{x} 100$ image. Migration assay is used to detect the ability of cells to metastasize and invasion assay is used to detect the ability of cells to lyse the cell matrix.

Scratch test. The cells were seeded into a 6-well plate at the density of $2 \times 10^{5}$ cells/well and cultured until $90 \%$ confluent. Three lines were scratched on the monolayers with a $200 \mu 1$ sterile pipette tip and were cultivated in serum-free medium. The scratched area was measured using ImageJ (v1.53, National Institutes of Health) at 0,12, 24 and $48 \mathrm{~h}$ and the migration rate was calculated as (scratch area at $0 \mathrm{~h}$-scratch area at $12,24,48 \mathrm{~h}) / \mathrm{scratch}$ area at $0 \mathrm{~h} \mathrm{x100 \%}$.

Co-immunoprecipitation (Co-IP). Co-IP was performed with anti-c-Myc (1:1,000; Proteintech; cat. no. 67447-1-Ig) and anti-RPL11 (1:1,000; Proteintech; cat. no. 16277-1-AP) antibodies using the Classic Magnetic Protrin A/G IP/Co-IP kit (Epizyme, Inc.) according to the manufacturer's protocol. The kit contained Protein A/G magnetic beads, lysis/wash buffer, SDS-PAGE protein loading buffer (5X), elution buffer, neutralization buffer. Lysis/wash buffer and PMSF (1:100, Solarbio, $\mathrm{P} 0100)$ were added at a ratio of $30 \mu \mathrm{l}$ per $1.0 \times 10^{5}$ cells, mixed well and incubated on ice for 30 min (mixing several times during this period); collected by centrifugation $\left(4^{\circ} \mathrm{C}\right.$; $12,000 \mathrm{x} \mathrm{g} ; 10 \mathrm{~min}$ ) with supernatant placed on ice for later use. Then $500 \mu 1$ of the prepared sample was added to a $1.5 \mathrm{ml} \mathrm{EP}$ tube, followed by $4 \mu \mathrm{g}$ antibody and incubated on a flip mixer $\left(4^{\circ} \mathrm{C}\right.$ overnight $)$ to form antigen-antibody complexes. Magnetic bead suspension $(25 \mu \mathrm{l})$ was placed into a $1.5 \mathrm{ml} \mathrm{EP}$ tube and $500 \mu 1$ of lysis/wash buffer added, the magnetic beads were resuspended by gently pipetting and then let stand on a magnetic stand for $1 \mathrm{~min}$. When the magnetic beads were adsorbed to the sidewall of the EP tube, the supernatant was aspirated and this step repeated twice. The antigen-antibody complex was added to the pretreated magnetic beads and incubated on an inversion mixer $\left(4^{\circ} \mathrm{C}\right.$ overnight). Then it was stood on the magnetic stand for 1 min, until the magnetic beads were adsorbed on the side wall of the EP tube. The supernatant was aspirated and discarded and what remained in the centrifuge tube was the antigen-antibody-magnetic bead complex. Lysis/rinse buffer $(500 \mu 1)$ was added to the antigen-antibody-magnetic bead complex, the magnetic beads resuspended by gently pipetting and agitation and then allowed to stand on the magnetic stand for 1 min until the magnetic beads were adsorbed to the sidewall of the centrifuge tube. The supernatant was aspirated and discarded and this step repeated twice. An appropriate amount of 5XSDS-PAGE loading buffer was added to the antigen-antibody-magnetic bead complex, mixed well and heated at $100^{\circ} \mathrm{C}$ for $10 \mathrm{~min}$. Following cooling, the EP tube was placed on a magnetic stand for $1 \mathrm{~min}$. After the magnetic beads were adsorbed on the side wall of the EP tube, the supernatant was collected and detected by SDS-PAGE. The immuno-precipitates were detected by western blotting as described above.

Luciferase activity assay. The dual-luciferase reporter gene detected the relationship between the transcription factor c-Myc and the Snail promoter and the 3'untranslated regions (UTRs) 2,000 bp upstream of the Snail transcription start site. The RPL11 and c-Myc overexpression plasmids and the luciferase SNAIL-pro reporter plasmid and Renilla luciferase plasmid were designed and constructed by Sangon Biotech Co., Ltd. LipoFiter 3.0 (Hanbio Biotechnology Co., Ltd.) was used for transfection according to the manufacturer's protocol. The BT549 cells were co-transfected with these constructs and lysed $48 \mathrm{~h}$ after transfection. Luciferase activity was measured using a luciferase detection kits (TransGen Biotech Co., Ltd.; cat. no. FR201-01) on a SpectraMax i3x Microplate Reader (Molecular Devices, LLC). The method of normalization was firefly luciferase activity comparison with Renilla luciferase activity.

Immunofluorescence. BT549 cells were seeded onto a round coverslip (Biosharp; cat. no. BS-14-RC) at the density of 2,000 cells/well. After $24 \mathrm{~h}$, the cells were fixed with $4 \%$ paraformaldehyde for $10 \mathrm{~min}$, permeabilized for with $2 \%$ Triton X-100 10 min, blocked in 10\% goat serum (Wuhan Boster Biological Technology, Ltd.; cat. no. AR0009) for 30 min (the above steps were carried out at room temperature) and then incubated overnight with anti-RRS1 (1:200, Abcam; cat. no. ab188161), anti-RPL11 (1:200, Proteintech; cat. no. 16277-1-AP), anti-c-Myc (1:50, Thermo, MA5-12080), anti-NPM (1:200, Proteintech; cat. no. 60096-1-Ig), anti-Lamin B1 (1:200, Proteintech 12987-1-AP) and anti-Fibrillarin/U3 RNP (1:200, ABclona; cat. no. A0850) at $4^{\circ} \mathrm{C}$. Subsequently, the cells were incubated with the appropriate fluorescent secondary antibody (1:200, ABclona; cat. no. AS039 and AS011) for $1 \mathrm{~h}$ at room temperature. Nuclei were stained using DAPI (Beijing Solarbio Science \& Technology Co., Ltd.; cat. no. C0065) for $10 \mathrm{~min}$ at room temperature according to the manufacturer's protocol. The stained cells were viewed with a laser-scanning confocal microscope (Leica Stellaris 5; Leica Microsystems $\mathrm{GmbH}$ ), 3 fields of view were randomly selected, observed and images captured at x200 and x630 magnification. 
Cellular fractionation. BT549 cells were harvested and 6×10 6 cells were resuspended in $500 \mu$ l hypotonic buffer. After $10 \mathrm{~min}$ incubation on ice, they were centrifuged at $500 \mathrm{x} \mathrm{g}$ for 10 min at $4^{\circ} \mathrm{C}$, and the supernatant containing the cytoplasmic fraction aspirated. The precipitate was resuspended in $300 \mu \mathrm{l}$ $\mathrm{S} 1$ buffer, layered on $300 \mu \mathrm{l} \mathrm{S} 2$ buffer and centrifuged at $4^{\circ} \mathrm{C}$, $1,500 \mathrm{x} \mathrm{g}$ for $5 \mathrm{~min}$. The precipitated nuclear fraction was resuspended in $300 \mu \mathrm{l} \mathrm{S} 2$ buffer, sonicated for $30 \mathrm{sec}$ with $60 \mathrm{sec}$ intervals for 5 cycles at $4^{\circ} \mathrm{C}, 25 \mathrm{kHz}, 60 \mathrm{~W}$, layered on $300 \mu \mathrm{l} \mathrm{S} 3$ buffer and centrifuged at $4^{\circ} \mathrm{C}, 3,000 \mathrm{x} \mathrm{g}$ for $10 \mathrm{~min}$. The nucleoplasmic fraction in the supernatant was separated and the precipitated nucleolar fraction was resuspended in RIPA buffer. Protease inhibitor cocktail was added throughout.

Reagent composition:

Hypotonic buffer: $10 \mathrm{mM}$ HEPES (pH 7.9), $10 \mathrm{mM} \mathrm{KCl,}$ $1.5 \mathrm{mM} \mathrm{MgCl}_{2}, 0.5 \mathrm{mM}$ DTT

S1 buffer: $0.25 \mathrm{M}$ sucrose, $10 \mathrm{mM} \mathrm{MgCl}_{2}$

S2 buffer: $0.35 \mathrm{M}$ sucrose, $0.5 \mathrm{mM} \mathrm{MgCl}_{2}$

S3 buffer: $0.88 \mathrm{M}$ sucrose, $0.05 \mathrm{mM} \mathrm{MgCl}_{2}$

Statistical analyses. The data was analyzed using the SPSS v13.0 program (SPSS, Inc.). All data was expressed as mean \pm standard deviation (SD) and statistical significance was determined through one-way ANOVA analysis with Bonferroni post hoc test. $\mathrm{P}<0.05$ was considered to indicate a statistically significant difference. Each experiment was repeated three times.

\section{Results}

RRS1 is upregulated in breast cancer cell lines. Tumor cells have a significantly higher rate of ribosome biosynthesis compared to normal cells in order to sustain rapid proliferation, which coincides with increased levels of RRS1. Consistent with this, we found that the expression of RRS1 mRNA and protein were significantly higher in four breast cancer cell lines (MDA-MB-231, BT549, MDA-MB-468 and MCF-7) compared to normal mammary epithelial cells (HMEC; Fig. 1A) and the highest levels were detected in the BT549 cells (Fig. 1B and C). Fibrillarin/U3 RNP as a nucleolar marker can accurately locate the nucleolus, immunofluorescence assay using in BT549 cells indicated that RRS1 was mainly located in the nucleus and nucleolus, followed by the cytoplasm (Fig. 1D). The sub-cellular localization of RRS1 was consistent with its role in ribosome biosynthesis.

RRS1 knockdown inhibited the proliferation, invasion and metastasis of BT549 cells. To determine the biological relevance of RRS1 in breast cancer progression, the present study knocked down RRS1 in BT-549 cells using an sh-RNA construct (Fig. 2A) and the knockdown efficiency was validated by the reduced protein and mRNA levels of RRS1 (Fig. 2B-D). RRS1 knockdown significantly decreased cell proliferation rates (Fig. 2E), as well as the migration and invasion abilities in vitro (Fig. 2F-K). Similarly, in the triple-negative breast cancer cell line MDA-MB-231, knocking down RRS1 also inhibited its invasion and metastasis ability (Fig. S1). Taken together, RRS1 is a key factor promoting the malignant phenotype of breast cancer cells.
RRS1 knockdown disrupted the ribosome assembly by altering the cellular localization of RPL11. RRS1 recruits RPL11 to the nucleolus during the synthesis of large ribosomal subunits, which are then exported to the cytoplasm for further maturation. Cytoplasmic and nuclear proteins were analyzed to determine whether RRS1 affected the cellular localization of RPL11 and it was found that knocking down RRS1 did not alter the levels of RPL11 in the cytoplasmic or nuclear fractions (Fig. 3A and B). By contrast, RRS1 knockdown significantly decreased RPL11 levels in the nucleolus and increased that it in nucleoplasm (Fig. 3C). Real disengages the Rsa4 and Rpf2/RRS1 complex from Pre-60S, which converts 5S RNP to the correct configuration and exports it out of the nucleus. Deletion of RRS1 can inhibit the interaction between Rea1 and Rsa4 (50). Consistent with this, the present study found that the knockdown of RRS1 significantly decreased the interaction of RPL23 (a marker protein of Pre-60S) with RPL11 and RPL5 (Fig. 3D). Taken together, RRS1 disrupted ribosomal assembly by preventing the incorporation of RPL11 into the Pre-60S subunit, which in turn led to its dissociation into the nucleoplasm. The dissociation of RPL11 from the ribosomal complex allows it to bind to c-Myc and inhibit its transactivation (41). There is also evidence that RRS1 knockout inhibits the nuclear export of RPL11 and increases its accumulation in the nucleus (30). Consistent with these previous observations, the present study found that RRS1 knockdown significantly enhanced the interaction between RPL11 and c-Myc (Fig. 3E and F). Furthermore, the absence of RRS1 also increased the c-Myc accumulation in the nucleus, with a concomitant decrease in its cytoplasmic levels (Fig. 3A and B). These findings suggested that knocking down RRS1 enhances the interaction between RPL11 and c-Myc.

RPL11 inhibits c-Myc-driven SNAIL transcription. A previous study showed that c-Myc could promote the EMT, invasion and metastasis of tumor cells by activating the mesenchymal transcription factor SNAIL (51). As RPL11 inhibits c-Myc transactivation (38), the present study next examined whether RPL11 also affected c-Myc-dependent SNAIL transcription using the luciferase reporter assay. As shown in Fig. 4, while overexpression of c-Myc increased luciferase activity in 293T cells, the expression of RPL11 inhibited the function of c-Myc and reduced the increase in luciferase activity (Fig. 4). This indicated that RPL11 reduces SNAIL transcription by inhibiting c-Myc activity and may therefore block the EMT process.

RPL11 inhibits EMT during RRS1 knockdown. EMT is a dynamic process in which serves an important role in tumor invasion and metastasis. Consistent with our hypothesis, RRS1 knockdown increased the expression of the epithelial marker E-cadherin (Fig. 5) and Cytokeratin (Fig. S2) and reduced that of the mesenchymal markers such as SNAIL, N-cadherin and vimentin in BT549 cell (Fig. 5). Simultaneous knockdown of RRS1 and RPL11 restored the levels of the mesenchymal markers and downregulated E-cadherin (Fig. 5). Similar results were obtained in the MDA-MB-231 cell line (Fig. S3). Taken together, RRS1 may promotes EMT of breast cancer cells through the RPL11-c-Myc axis, which in turn promotes tumor invasion and metastasis. 
A

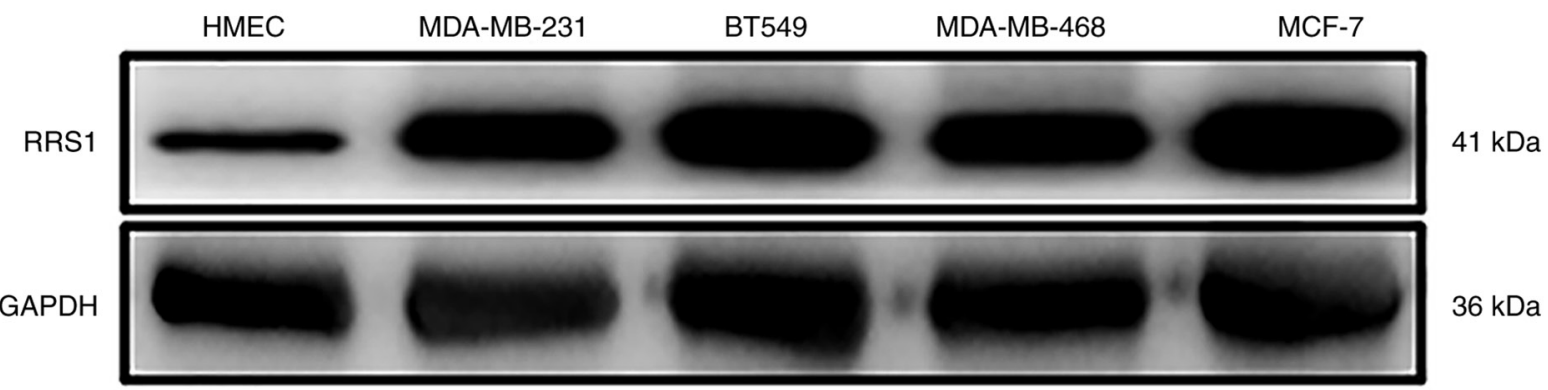

B

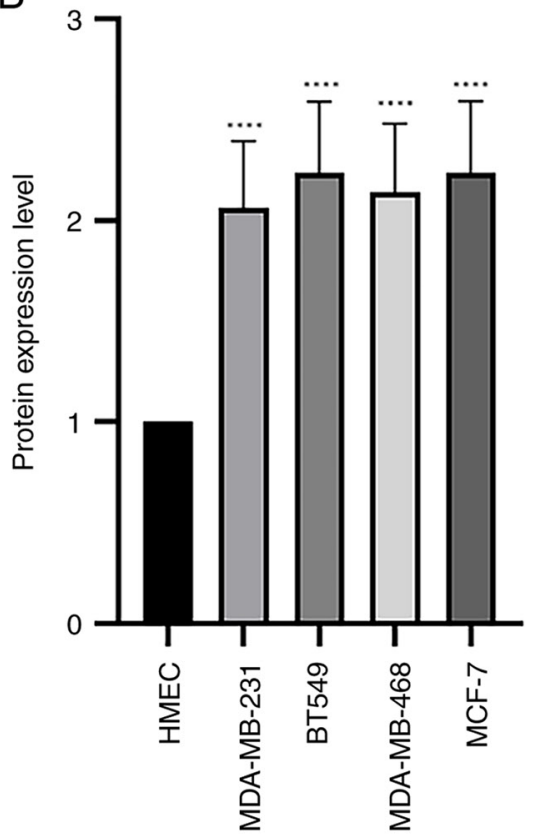

C

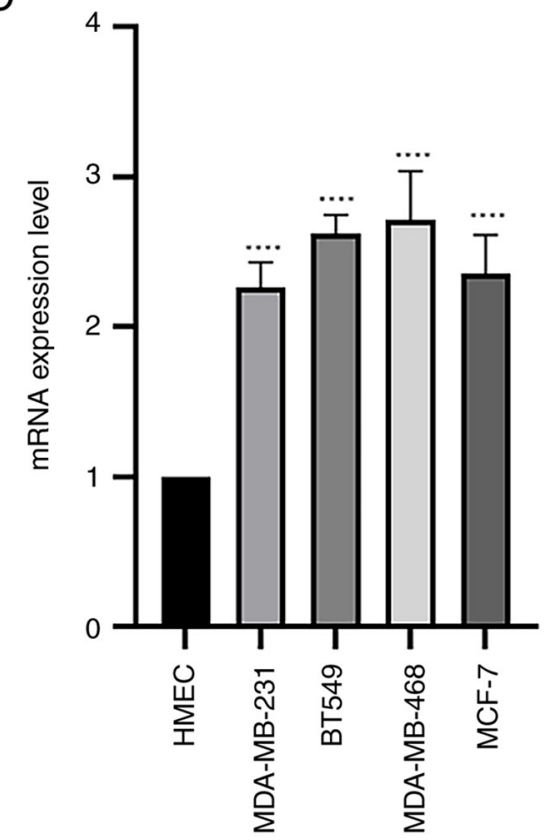

$\mathrm{D}$
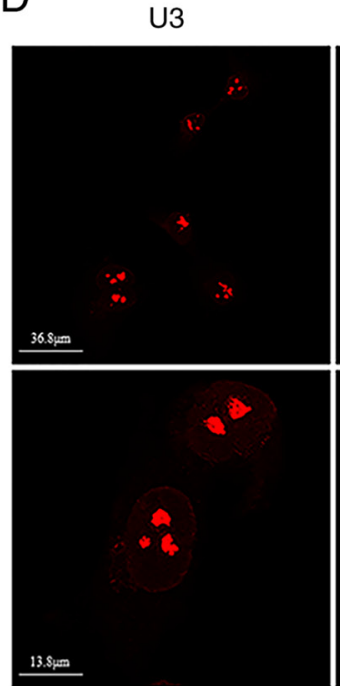

RRS1
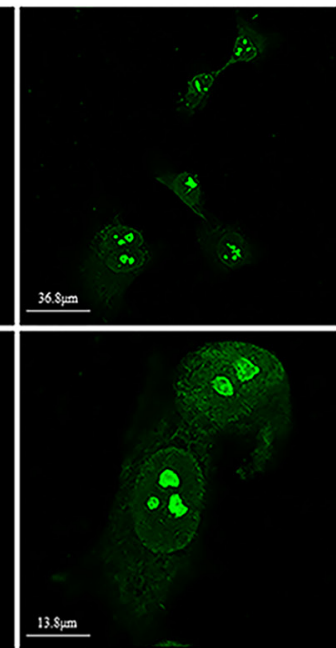

DAPI
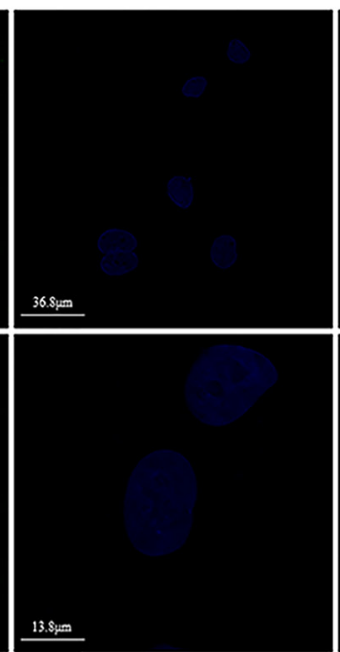
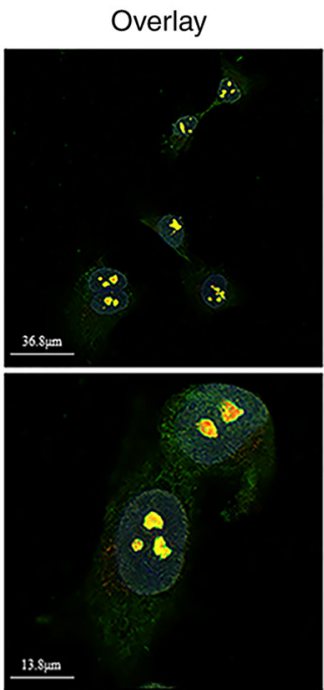

Figure 1. Expression and localization of RRS1 in breast cancer cells. (A) and (B) protein expression of RRS1 in normal human breast epithelial cells and breast cancer cell lines. (C) The mRNA content of RRS1 in normal human breast epithelial cells and breast cancer cell lines as detected by quantitative PCR. (D) The localization of RRS1 in BT549 cells as detected by immunofluorescence. ${ }^{* * * *} \mathrm{P}<0.0001$. RRS1, regulator of ribosome synthesis 1.

\section{Discussion}

Breast cancer has a high mortality rate due to its metastatic nature (52). The clinical outcomes of surgery, radiotherapy, chemotherapy, endocrine therapy and targeted therapy are sub-optimal and the survival rate of breast cancer patients remains poor (53). The aim of the present study was to determine the role and underlying mechanism of RRS1 in the invasion and metastasis of breast cancer cells.

Increased ribosome biosynthesis is a prerequisite for sustaining the high proliferation rates of tumor cells $(54,55)$. RRS1 is a regulator of ribosome biosynthesis and shows high 

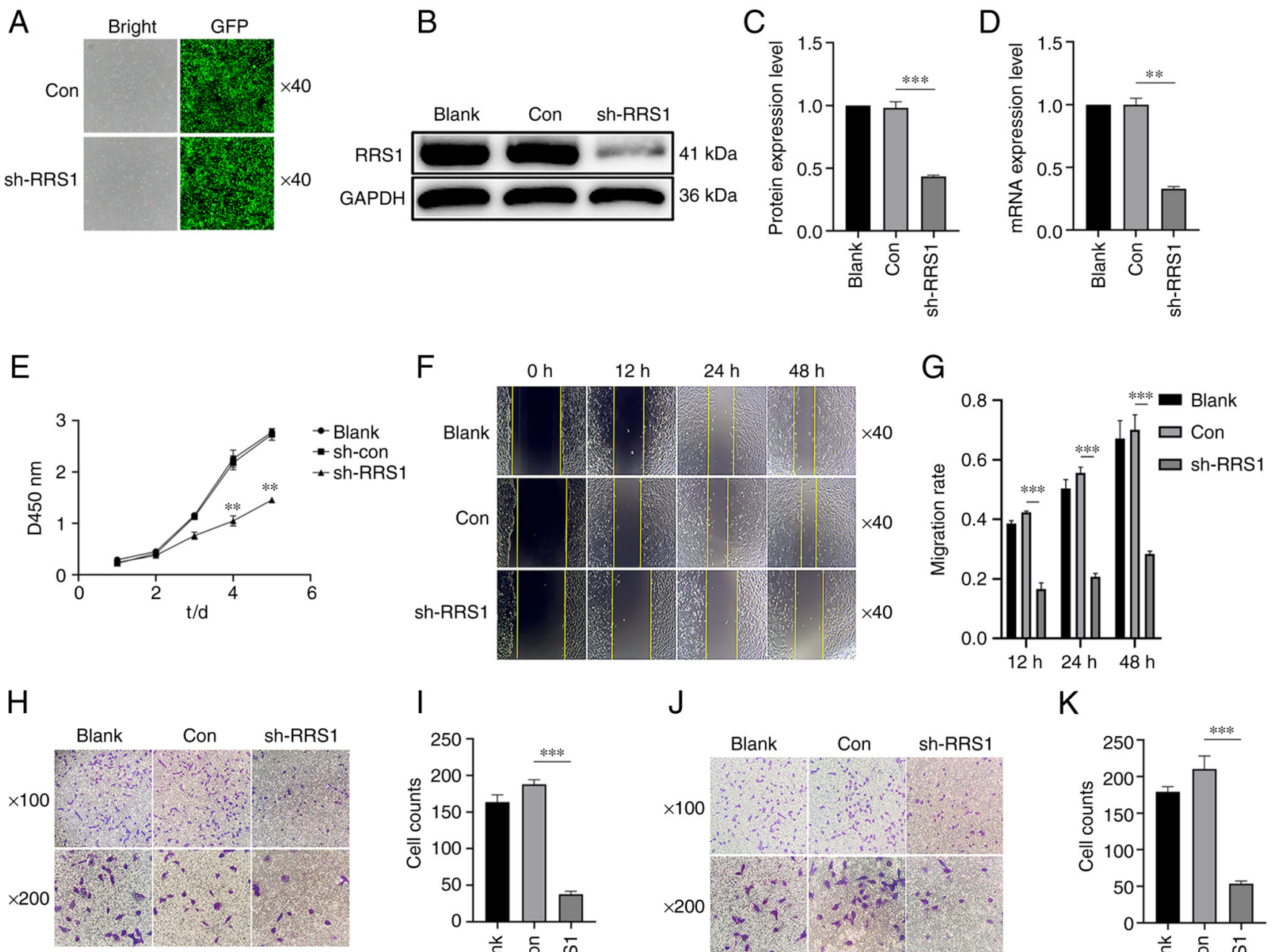

I

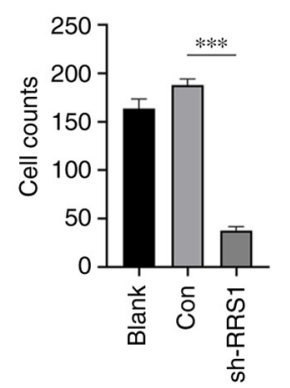

$\mathrm{J}$

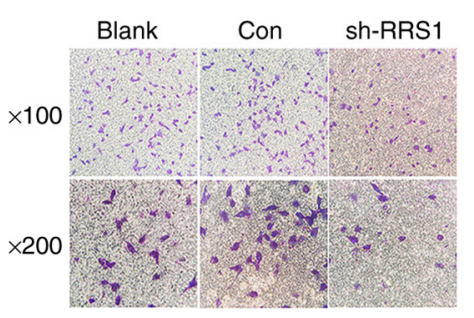

$\mathrm{K}$

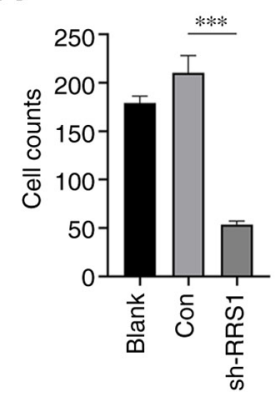

Figure 2. The function of RRS1 in breast cancer cells. (A) The lentivirus transfection efficiency of BT549 cells was observed by fluorescence microscope. (B and C) Western blotting detected the expression of RRS1 protein. (D) RRS1 mRNA was detected by quantitative PCR. (E) CCK-8 was used to detect the proliferation of BT549. (F and G) Knockdown of the expression of RRS1 in BT549 cells and the migration of cells was detected by scratch test. ( $\mathrm{H}$ and $\mathrm{I})$ Transwell experiment were used to detect cell migration. ( $\mathrm{J}$ and $\mathrm{K}$ ) Invasion experiment was used to detect cell invasion, ${ }^{* *} \mathrm{P}<0.01,{ }^{* * *} \mathrm{P}<0.001$. RRS1, regulator of ribosome synthesis 1 ; Con, control; sh, short interfering.

expression levels in multiple tumors (14,24-28,30). Likewise, the present study also detected significantly higher levels of RRS1 in the breast cancer cell lines compared to normal breast epithelial cells. Knocking down RRS1 inhibited the invasion, migration and proliferation of BT549 cells, indicating that RRS1 functions as an oncogene in breast cancer. From a previous study, miRNA-148a inhibits proliferation, migration and invasion by downregulating the expression of RRS1 and promotes the apoptosis of cervical cancer cells (23). RRS1 forms a complex with Rpf2, which recruits 5S RNP onto the Pre-60S subunit. RPL5 also interacts with Rsa4, which integrates the 5S RNP onto Pre-60S (56). Subsequently, Rea1, an AAA+ (ATPases associated with various cellular activities) family member, interacts with the ubiquitin-like (UBL) domain of Rsa4 and releases Rsa4 in an ATP-dependent manner, which is followed by the release of the Rpf2/RRS1 complex $(50,57,58)$. This rotates the conformation of $5 \mathrm{~S}$ RNP, which fixes it on Pre-60S and is necessary for Pre-60S export. RRS1 ensures correct binding of the Rsa4 UBL domain with Rea1 (50). In the absence of RRS1 therefore, Pre-60S maturation is blocked and it is released from the nucleolus to the nucleoplasm and cannot be exported to the cytoplasm $(18,50)$. The present study found that while RRS1 knockdown did not affect the total content of RPL11, it shifted the localization of RPL11 from the nucleolus to the nucleoplasm. Consistent with this, RPL23 also accumulated in the nucleus after RRS1 knockdown. In addition, deletion of RRS1 is known to inhibit the incorporation of RPL11 and RPL5 into Pre-60S, thereby affecting Pre-60S assembly (18). Taken together, RRS1 depletion prevents the incorporation of 5S RNP into Pre-60S, which hinders the nuclear export of pre ribosomes and inhibits ribosome biosynthesis.

$\mathrm{C}-\mathrm{Myc}$ is a pro-survival protein (59), which is often overexpressed in tumor cells $(60,61)$. RPL11 can regulate the expression of c-Myc at both mRNA and protein levels $(38,62)$. Dai et al $(38)$ found that RPL11 could bind to the Myc box II (MB II) of c-Myc at c-Myc target gene promoter and inhibit the histone $\mathrm{H} 4$ acetylation at c-Myc target nucleolin gene promoter and recruitment of c-Myc coactivator TRRAP, finally reducing the transcription of the c-Myc downstream target gene. In addition, RPL11 can bind 
A
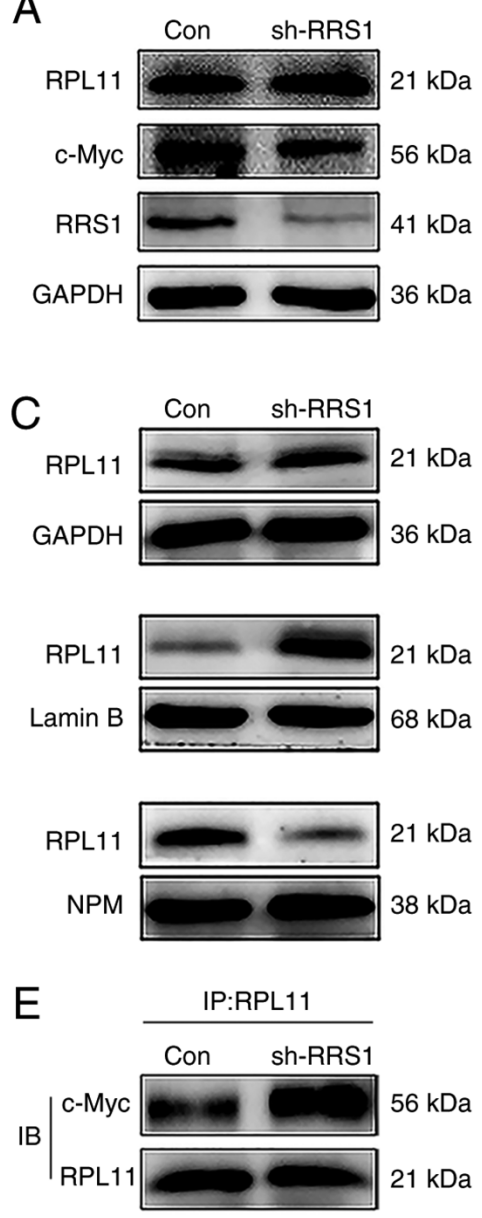

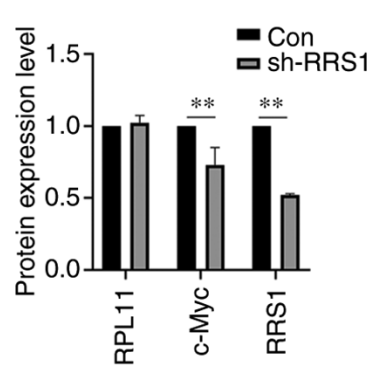

B
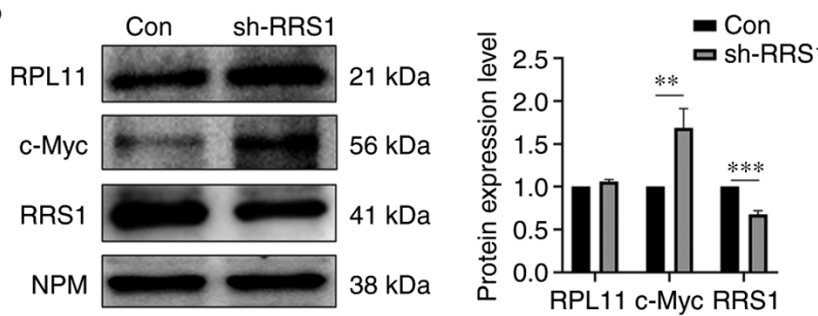
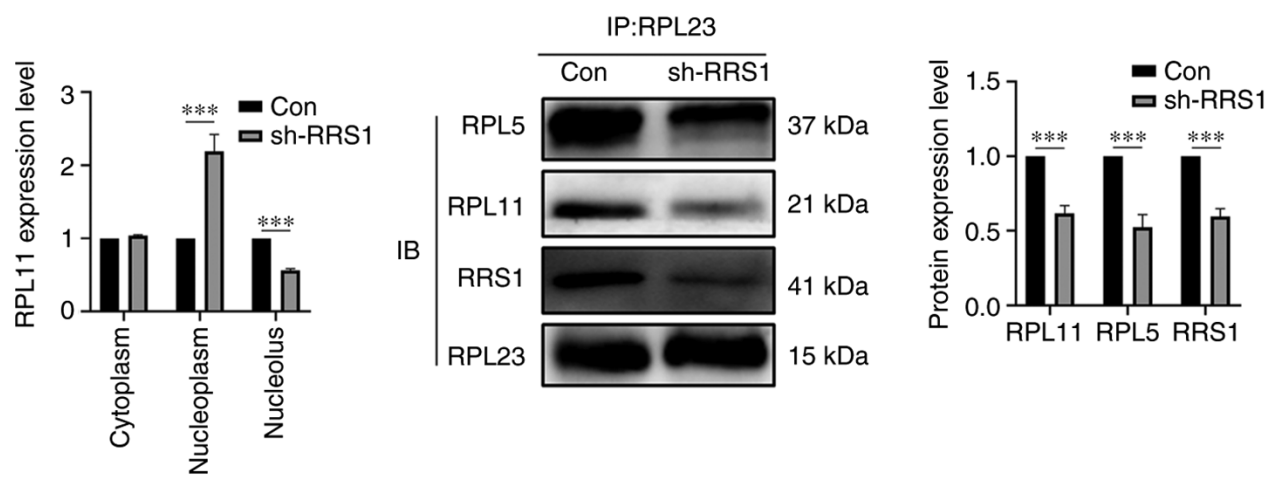
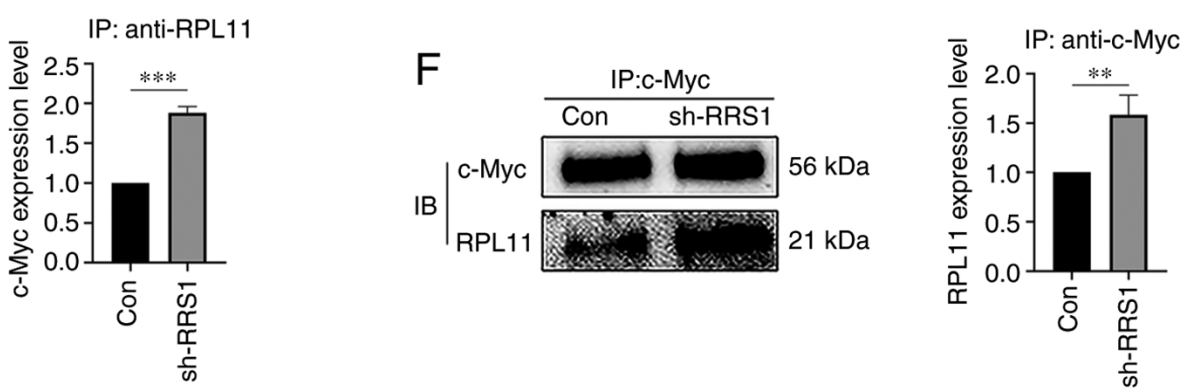

Figure 3. RRS1 affects the localization of RPL11 in the nucleus and the interaction between RPL11 and c-Myc. Cytoplasmic proteins and nuclear proteins were isolated after knocking down of RRS1 to detect the changes of RPL11 and c-Myc in (A) cytoplasm and (B) nucleus. Cytoplasmic protein and nuclear protein used GAPDH and NPM as reference, respectively. (C) The changes of RPL11 in each cell component after knocking down of RRS1. GAPDH is used as cytoplasmic control, Lamin B is used as nucleoplasmic control and NPM as nucleolar control. (D) Co-IP was performed using anti-RPL23 antibody and the effect of silencing RRS1 on Pre-60S assembly detected. (E and F) Co-IP was conducted using anti-RPL11 antibody or anti-c-Myc antibody to detect the effect of knockdown RRS1 on the interaction between RPL11 and c-Myc, ${ }^{* *} \mathrm{P}<0.01,{ }^{* * *} \mathrm{P}<0.001$. RRS1, regulator of ribosome synthesis 1; RPL11, ribosome protein L11; NPM, nucleophosmin; Co-IP, Co-immunoprecipitation.

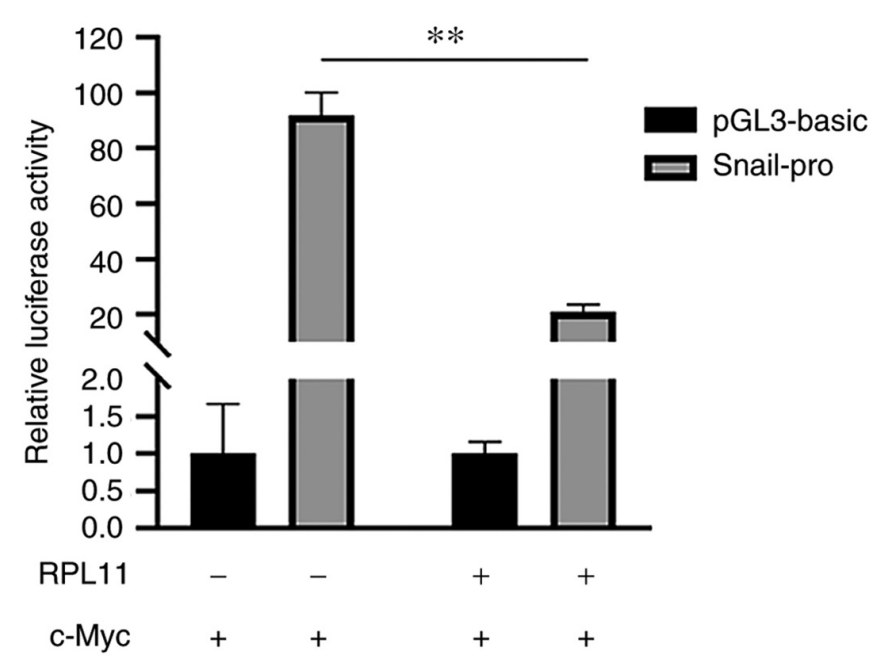

Figure 4. RPL11 inhibits c-Myc-dependent the activation of SNAIL promoter. Treated $293 \mathrm{~T}$ cells were transfected with plasmids for luciferase assays to determine the reporter activity, ${ }^{* * *} \mathrm{P}<0.001$. RPL11, ribosome protein L11. to 3'-UTR at c-Myc mRNA, recruit microRNA-induced silencing complex (miRISC) assembled by mir-24 and combine with Ago2 promote the interaction of miRISC and 3'-UTR, leading to c-Myc mRNA degradation (63). RPL11 and RPL5 can also suppress c-Myc expression in a synergistic manner (62). The present study found that RRS1 knockdown increased the interaction between RPL11 and c-Myc and inhibited the transactivation of SNAIL by c-Myc. Similarly, knocking down RRS1 reduced the levels of SNAIL, N-cadherin and VIM proteins and increased that of E-cadherin. Knockdown of RPL11 reversed the inhibitory effect of RRS1 deletion. Thus, RRS1 regulated the function of c-Myc and EMT of breast cancer cells through RPL11.

To summarize, the present study showed that RRS1 may promote the EMT and metastasis of breast cancer cells by regulating ribosome assembly and biosynthesis. Depletion of RRS1 prevented nuclear export of the Pre-60s subunit and increased the accumulation of RPL11 in the 


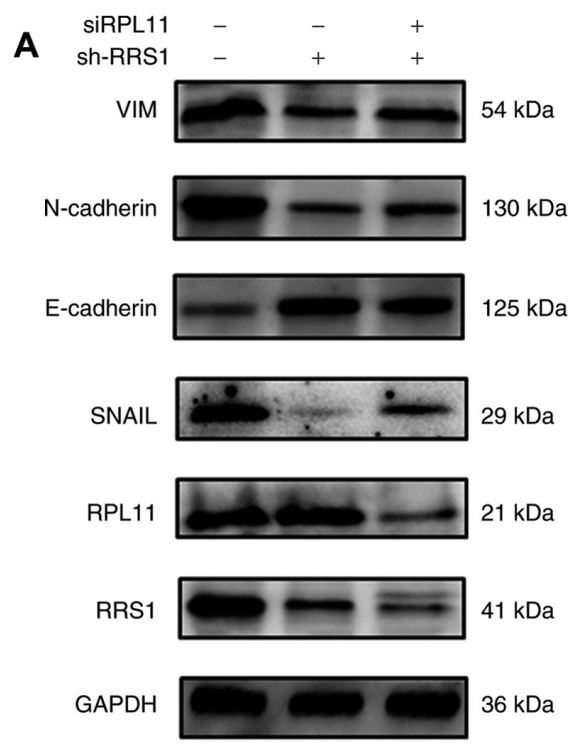

$\mathbf{B}$

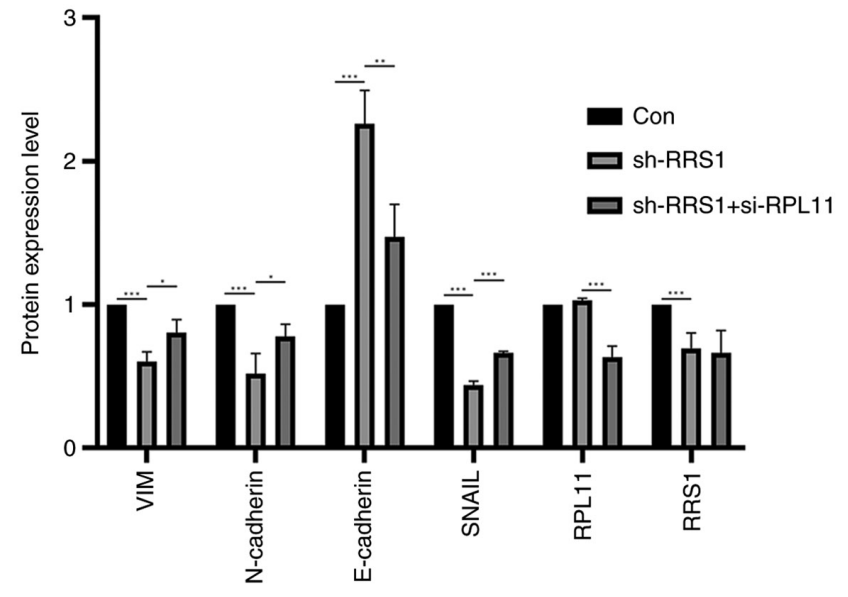

Figure 5. RPL11 reversed EMT which inhibited by RRS1 reduction. After knockdown of RRS1, cells were lysed to extract total protein and western blotting assays using indicated antibodies. (A) Depletion of RRS1 inhibited SNAIL and EMT processes. (B) RRS1 knockdown and used siRNA to interfere with RPL11 expression, reversing the inhibition of RRS1 depletion on SNAIL and EMT processes, ${ }^{*} \mathrm{P}<0.05,{ }^{* *} \mathrm{P}<0.01,{ }^{* * *} \mathrm{P}<0.001$. RPL11, ribosome protein L11; EMT, epithelial mesenchymal transition; RRS1, regulator of ribosome synthesis 1; VIM, vimentin; Con, control; si, short interfering; sh, short hairpin.

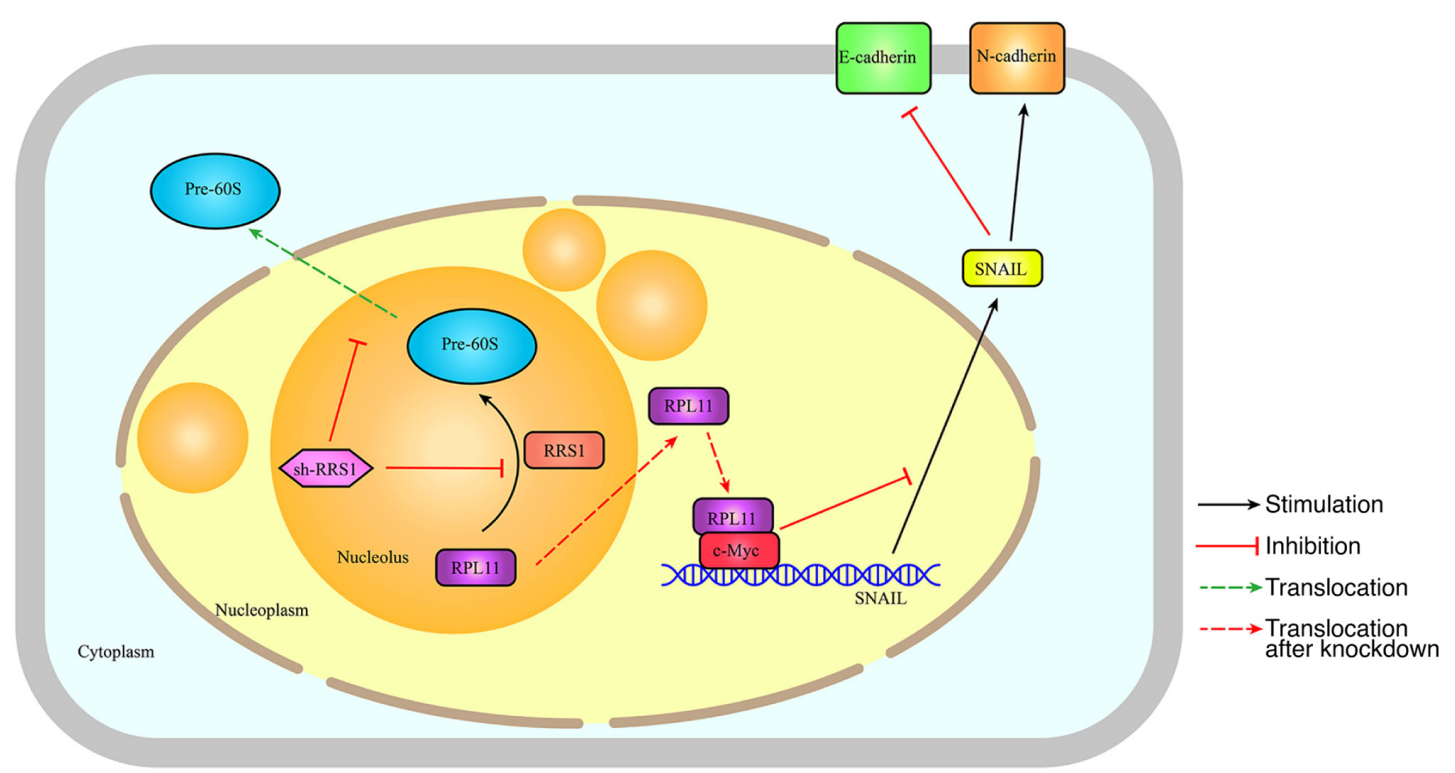

Figure 6. Schematic of mechanism for downregulation of RRS1 inhibiting invasion and metastasis of breast cancer (BT549) cells. Knockdown of RRS1 blocked RPL11 to assemble Pre-60S and the nuclear output of Pre-60S. RPL11 translocated from nucleolus to nucleoplasm and interacted with c-Myc to inhibit the transcription of SNAIL by c-Myc. Finally, it inhibited EMT to suppress BT549 cells invasion and metastasis. RRS1, regulator of ribosome synthesis 1; RPL11, ribosome protein L11.

nucleoplasm. This enhanced the interaction between RPL11 and c-Myc and decreased the transcription of the c-Myc target SNAIL, eventually inhibiting EMT (Fig. 6). Therefore, the RPL11-c-Myc-SNAIL axis may as a potential therapeutic target in breast cancer. However, it remains to expound the effect of RRS1 on the RPL11-c-Myc-SNAIL axis and its role in breast cancer.

\section{Acknowledgements}

Not applicable.

\section{Funding}

The present study was supported by the National Natural Science Foundation of China (grant no. 81472542) and Chinese Medicine Projects in Shandong Province (grant no. 2021Z036).

\section{Availability of data and materials}

All data generated or analyzed during this study are included in this published article. 


\section{Authors' contributions}

LH provided the study conception and design. RW analyzed the data, edited the figures and wrote the manuscript. $\mathrm{CP}$ and JS contributed to data curation. RW, YH, QW, LD, YC, JZ, LZ, LW performed the experiments. LH reviewed the manuscript. LH and RW confirm the authenticity of all the raw data. All authors contributed to the article and all authors reviewed and approved the final manuscript.

\section{Ethics approval and consent to participate}

Not applicable.

\section{Patient consent for publication}

Not applicable.

\section{Competing interests}

The authors declare that they have no competing interests.

\section{References}

1. Siegel RL, Miller KD, Fuchs HE and Jemal A: Cancer statistics, 2021. CA Cancer J Clin 71: 7-33, 2021.

2. Roulot A, Héquet D, Guinebretière JM, Vincent-Salomon A, Lerebours F, Dubot C and Rouzier R: Tumoral heterogeneity of breast cancer. Ann Biol Clin (Paris) 74: 653-660, 2016.

3. Yeo SK and Guan JL: Breast cancer: Multiple Subtypes within a Tumor? Trends Cancer 3: 753-760, 2017.

4. Gao JJ and Swain SM: Luminal A breast cancer and molecular assays: A review. Oncologist 23: 556-565, 2018.

5. Ades F, Zardavas D, Bozovic-Spasojevic I, Pugliano L, Fumagalli D, de Azambuja E, Viale G, Sotiriou C and Piccart M: Luminal B breast cancer: Molecular characterization, clinical management, and future perspectives. J Clin Oncol 32: 2794-2803, 2014.

6. Prat A, Pineda E, Adamo B, Galván P, Fernández A, Gaba L, Díez M, Viladot M, Arance A and Muñoz M: Clinical implications of the intrinsic molecular subtypes of breast cancer. Breast 24 (Suppl) 2: S26-S35, 2015.

7. Yin L, Duan JJ, Bian XW and Yu SC: Triple-negative breast cancer molecular subtyping and treatment progress. Breast Cancer Res 22: 61, 2020

8. Hao S, Ha L, Cheng G, Wan Y, Xia Y, Sosnoski DM, Mastro AM and Zheng SY: A Spontaneous 3D Bone-On-a-Chip for bone metastasis study of breast cancer cells. Small 14: e1702787, 2018.

9. Watase C, Shiino S, Shimoi T, Noguchi E, Kaneda T, Yamamoto Y, Yonemori K, Takayama S and Suto A: Breast cancer brain metastasis-overview of disease state, treatment options and future perspectives. Cancers (Basel) 13: 1078, 2021.

10. Maughan KL, Lutterbie MA and Ham PS: Treatment of breast cancer. Am Fam Physician 81: 1339-1346, 2010.

11. Elsayed M, Alhussini M, Basha A and Awad AT: Analysis of loco-regional and distant recurrences in breast cancer after conservative surgery. World J Surg Oncol 14: 144, 2016.

12. Salata C, deAlmeida CE, Ferreira-Machado SC, Barroso RC, Nogueira LP, Mantuano A, Pickler A, Mota CL and de Andrade CBV: Preliminary pre-clinical studies on the side effects of breast cancer treatment. Int J Radiat Biol 97: 877-887, 2021.

13. Taylor CW and Kirby AM: Cardiac Side-effects from breast cancer radiotherapy. Clin Oncol (R Coll Radiol) 27: 621-629, 2015.

14. Tsuno A, Miyoshi K, Tsujii R, Miyakawa T and Mizuta K: RRS1, a conserved essential gene, encodes a novel regulatory protein required for ribosome biogenesis in Saccharomyces cerevisiae. Mol Cell Biol 20: 2066-2074, 2000.

15. Hua Y, Song J, Peng C, Wang R, Ma Z, Zhang J, Zhang Z, Li N and Hou L: Advances in the relationship between regulator of ribosome Synthesis 1 (RRS1) and diseases. Front Cell Dev Biol 9: 620925, 2021.
16. Granneman S and Baserga SJ: Ribosome biogenesis: Of knobs and RNA processing. Exp Cell Res 296: 43-50, 2004.

17. Baßler J and Hurt E: Eukaryotic ribosome assembly. Annu Rev Biochem 88: 281-306, 2019.

18. Zhang J, Harnpicharnchai P, Jakovljevic J, Tang L, Guo Y, Oeffinger M, Rout MP, Hiley SL, Hughes T and Woolford JL Jr: Assembly factors Rpf 2 and Rrs1 recruit 5S rRNA and ribosomal proteins rpL5 and rpL11 into nascent ribosomes. Genes Dev 21: 2580-2592, 2007.

19. Gambe AE, Matsunaga S, Takata H, Ono-Maniwa R, Baba A, Uchiyama S and Fukui K: A nucleolar protein RRS1 contributes to chromosome congression. FEBS Lett 583: 1951-1956, 2009.

20. Horigome C, Okada T, Shimazu K, Gasser SM and Mizuta K: Ribosome biogenesis factors bind a nuclear envelope SUN domain protein to cluster yeast telomeres. EMBO J 30: 3799-3811, 2011.

21. Miyoshi K, Tsujii R, Yoshida H, Maki Y, Wada A, Matsui Y, Toh-E A and Mizuta K: Normal assembly of 60S ribosomal subunits is required for the signaling in response to a secretory defect in Saccharomyces cerevisiae. J Biol Chem 277: 18334-18339, 2002.

22. Carnemolla A, Fossale E, Agostoni E, Michelazzi S, Calligaris R, De Maso L, Del Sal G, MacDonald ME and Persichetti F: Rrs1 is involved in endoplasmic reticulum stress response in Huntington disease. J Biol Chem 284: 18167-18173, 2009.

23. Zhang Y, Sun B, Zhao L, Liu Z, Xu Z, Tian Y and Hao C: Up-regulation of miRNA-148a inhibits proliferation, invasion, and migration while promoting apoptosis of cervical cancer cells by down-regulating RRS1. Biosci Rep 39: BSR20181815, 2019.

24. Wang J, Li Z, Zuo C, Xie Q, Li H, Jia J, Zhen Z, Qi R, Li Z, Liu D and Sun B: Knockdown of RRS1 by lentiviral-mediated RNAi promotes apoptosis and suppresses proliferation of human hepatocellular carcinoma cells. Oncol Rep 38: 2166-2172, 2017.

25. Hua YN, Song JL, Ma ZL, Wu L, Zhang Z, Zhang L, Li N, Cong SB and Hou L: Effect of RRS1 gene knockdown on BT549 cell line proliferation and apoptosis in breast cancer. Neoplasma 66: 28-32, 2019.

26. Song J, Ma Z, Hua Y, Xu J, Li N, Ju C and Hou L: Functional role of RRS1 in breast cancer cell proliferation. J Cell Mol Med 22: 6304-6313, 2018

27. Chen F, Jin Y, Feng L, Zhang J, Tai J, Shi J, Yu Y, Lu J, Wang S, Li X, et al: RRS1 gene expression involved in the progression of papillary thyroid carcinoma. Cancer Cell Int 18: 20, 2018.

28. Wu XL, Yang ZW, He L, Dong PD, Hou MX, Meng XK, Zhao HP, Wang ZY, Wang F, Baoluri, et al: RRS1 silencing suppresses colorectal cancer cell proliferation and tumorigenesis by inhibiting $\mathrm{G} 2 / \mathrm{M}$ progression and angiogenesis. Oncotarget 8 : 82968-82980, 2017.

29. Ma Y, Yan F, Wei W, Deng J,Li L, Liu L and Sun J: MicroRNA-598 inhibits the growth and maintenance of gastric cancer stem-like cells by down-regulating RRS1. Cell Cycle 18: 2757-2769, 2019.

30. Cao P, Yang A, Li P, Xia X, Han Y, Zhou G, Wang R, Yang F, Li Y, Zhang Y, et al: Genomic gain of RRS1 promotes hepatocellular carcinoma through reducing the RPL11-MDM2-p53 signaling. Sci Adv 7: eabf4304, 2021.

31. Calviño FR, Kharde S, Ori A, Hendricks A, Wild K, Kressler D, Bange G, Hurt E, Beck M and Sinning I: Symportin 1 chaperones 5S RNP assembly during ribosome biogenesis by occupying an essential rRNA-binding site. Nat Commun 6: 6510, 2015.

32. Zhang Y, Wolf GW, Bhat K, Jin A, Allio T, Burkhart WA and Xiong Y: Ribosomal protein L11 negatively regulates oncoprotein MDM2 and mediates a p53-dependent ribosomal-stress checkpoint pathway. Mol Cell Biol 23: 8902-8912, 2003.

33. Haupt Y, Maya R, Kazaz A and Oren M: Mdm2 promotes the rapid degradation of p53. Nature 387: 296-299, 1997.

34. Momand J, Zambetti GP, Olson DC, George D and Levine AJ: The mdm-2 oncogene product forms a complex with the p53 protein and inhibits p53-mediated transactivation. Cell 69: 1237-1245, 1992.

35. Bursać S, Brdovčak MC, Pfannkuchen M, Orsolić I, Golomb L, Zhu Y, Katz C, Daftuar L, Grabušić K, Vukelić I, et al: Mutual protection of ribosomal proteins L5 and L11 from degradation is essential for p53 activation upon ribosomal biogenesis stress. Proc Natl Acad Sci USA 109: 20467-20472, 2012.

36. Horn HF and Vousden KH: Cooperation between the ribosomal proteins L5 and L11 in the p53 pathway. Oncogene 27: 5774-5784, 2008.

37. Wang HT, Chen TY, Weng CW, Yang CH and Tang MS: Acrolein preferentially damages nucleolus eliciting ribosomal stress and apoptosis in human cancer cells. Oncotarget 7: 80450-80464, 2016. 
38. Dai MS, Arnold H, Sun XX, Sears R and Lu H: Inhibition of c-Myc activity by ribosomal protein L11. EMBO J 26: 3332-3345, 2007.

39. van Riggelen J, Yetil A and Felsher DW: MYC as a regulator of ribosome biogenesis and protein synthesis. Nat Rev Cancer 10: 301-309, 2010.

40. Dai MS, Sears R and Lu H: Feedback regulation of c-Myc by ribosomal protein L11. Cell Cycle 6: 2735-2741, 2007.

41. Wang X, Ren Y, Wang Z, Xiong X, Han S, Pan W, Chen H, Zhou L, Zhou C, Yuan Q and Yang M: Down-regulation of 5S rRNA by miR-150 and miR-383 enhances c-Myc-rpL11 interaction and inhibits proliferation of esophageal squamous carcinoma cells. FEBS Lett 589: 3989-3997, 2015.

42. Gao X, Liu X, Lu Y, Wang Y, Cao W, Liu X, Hu H and Wang H: PIM1 is responsible for IL-6-induced breast cancer cell EMT and stemness via c-myc activation. Breast Cancer 26: 663-671, 2019.

43. Yang J, Wu SP, Wang WJ, Jin ZR, Miao XB, Wu Y, Gou DM, Liu QZ and Yao KT: A novel miR-200c/c-myc negative regulatory feedback loop is essential to the EMT process, CSC biology and drug sensitivity in nasopharyngeal cancer. Exp Cell Res 391 : $111817,2020$.

44. Tao L, Shu-Ling W, Jing-Bo H, Ying Z, Rong $H$, Xiang-Qun L, Wen-Jie C and Lin-Fu Z: MiR-451a attenuates doxorubicin resistance in lung cancer via suppressing epithelialmesenchymal transition (EMT) through targeting c-Myc. Biomed Pharmacother 125: 109962, 2020.

45. Liu N, Wang Z, Liu D and Xie P: HOXC13-AS-miR-122-5p-S ATB1-C-Myc feedback loop promotes migration, invasion and EMT process in glioma. Onco Targets Ther 12: 7165-7173, 2019.

46. Lin X, Sun R, Zhao X, Zhu D, Zhao X, Gu Q, Dong X, Zhang D, Zhang Y, Li Y and Sun B: C-myc overexpression drives melanoma metastasis by promoting vasculogenic mimicry via c-myc/snail/Bax signaling. J Mol Med (Berl) 95: 53-67, 2017.

47. Wang K, Zheng J, Yu J, Wu Y, Guo J, Xu Z and Sun X: Knockdown of MMP-1 inhibits the progression of colorectal cancer by suppressing the PI3K/Akt/c-myc signaling pathway and EMT. Oncol Rep 43: 1103-1112, 2020.

48. Nieto MA, Huang RY, Jackson RA and Thiery JP: EMT: 2016. Cell 166: 21-45, 2016.

49. Livak KJ and Schmittgen TD: Analysis of relative gene expression data using real-time quantitative PCR and the 2(-Delta Delta C(T)) method. Methods 25: 402-408, 2001

50. Madru C, Lebaron S, Blaud M, Delbos L, Pipoli J, Pasmant E, Réty S and Leulliot N: Chaperoning 5S RNA assembly. Genes Dev 29: 1432-1446, 2015.

51. Smith AP, Verrecchia A, Fagà G, Doni M, Perna D, Martinato $F$, Guccione E and Amati B: A positive role for Myc in TGFbeta-induced Snail transcription and epithelial-to-mesenchymal transition. Oncogene 28: 422-430, 2009.

52. Azamjah N, Soltan-Zadeh Y and Zayeri F: Global trend of breast cancer mortality rate: A 25-year study. Asian Pac J Cancer Prev 20: 2015-2020, 2019.
53. Henson KE, McGale P, Darby SC, Parkin M, Wang Y and Taylor CW: Cardiac mortality after radiotherapy, chemotherapy and endocrine therapy for breast cancer: Cohort study of 2 million women from 57 cancer registries in 22 countries. Int J Cancer 147: 1437-1449, 2020.

54. Penzo M, Montanaro L, Treré D and Derenzini M: The ribosome biogenesis-cancer connection. Cells 8: 55, 2019.

55. Nait Slimane S, Marcel V, Fenouil T, Catez F, Saurin JC, Bouvet P, Diaz JJ and Mertani HC: Ribosome biogenesis alterations in colorectal cancer. Cells 9: 2361, 2020.

56. Baßler J, Paternoga H, Holdermann I, Thoms M, Granneman S, Barrio-Garcia C, Nyarko A, Lee W, Stier G, Clark SA, et al: A network of assembly factors is involved in remodeling rRNA elements during preribosome maturation. J Cell Biol 207: 481-498, 2014.

57. Ulbrich C, Diepholz M, Bassler J, Kressler D, Pertschy B, Galani K, Böttcher B and Hurt E: Mechanochemical removal of ribosome biogenesis factors from nascent $60 \mathrm{~S}$ ribosomal subunits. Cell 138: 911-922, 2009.

58. Micic J, Li Y, Wu S, Wilson D, Tutuncuoglu B, Gao N and Woolford JL Jr: Coupling of 5S RNP rotation with maturation of functional centers during large ribosomal subunit assembly. Nat Commun 11: 3751, 2020.

59. Davis AC, Wims M, Spotts GD, Hann SR and Bradley A: A null c-myc mutation causes lethality before 10.5 days of gestation in homozygotes and reduced fertility in heterozygous female mice. Genes Dev 7: 671-682, 1993.

60. Destefanis F, Manara V and Bellosta P: Myc as a regulator of ribosome biogenesis and cell competition: A link to cancer. Int J Mol Sci 21: 4037, 2020.

61. Wu H, Yang TY, Li Y, Ye WL, Liu F, He XS, Wang JR, Gan WJ, Li XM, Zhang S, et al: Tumor necrosis factor receptor-associated Factor 6 promotes hepatocarcinogenesis by interacting with histone deacetylase 3 to enhance c-Myc Gene expression and protein stability. Hepatology 71: 148-163, 2020.

62. Liao JM, Zhou X, Gatignol A and Lu H: Ribosomal proteins L5 and L11 co-operatively inactivate c-Myc via RNA-induced silencing complex. Oncogene 33: 4916-4923, 2014.

63. Challagundla KB, Sun XX, Zhang X, DeVine T, Zhang Q, Sears RC and Dai MS: Ribosomal protein L11 recruits $\mathrm{miR}-24 / \mathrm{miRISC}$ to repress c-Myc expression in response to ribosomal stress. Mol Cell Biol 31: 4007-4021, 2011.

This work is licensed under a Creative Commons Attribution-NonCommercial-NoDerivatives 4.0 International (CC BY-NC-ND 4.0) License. 